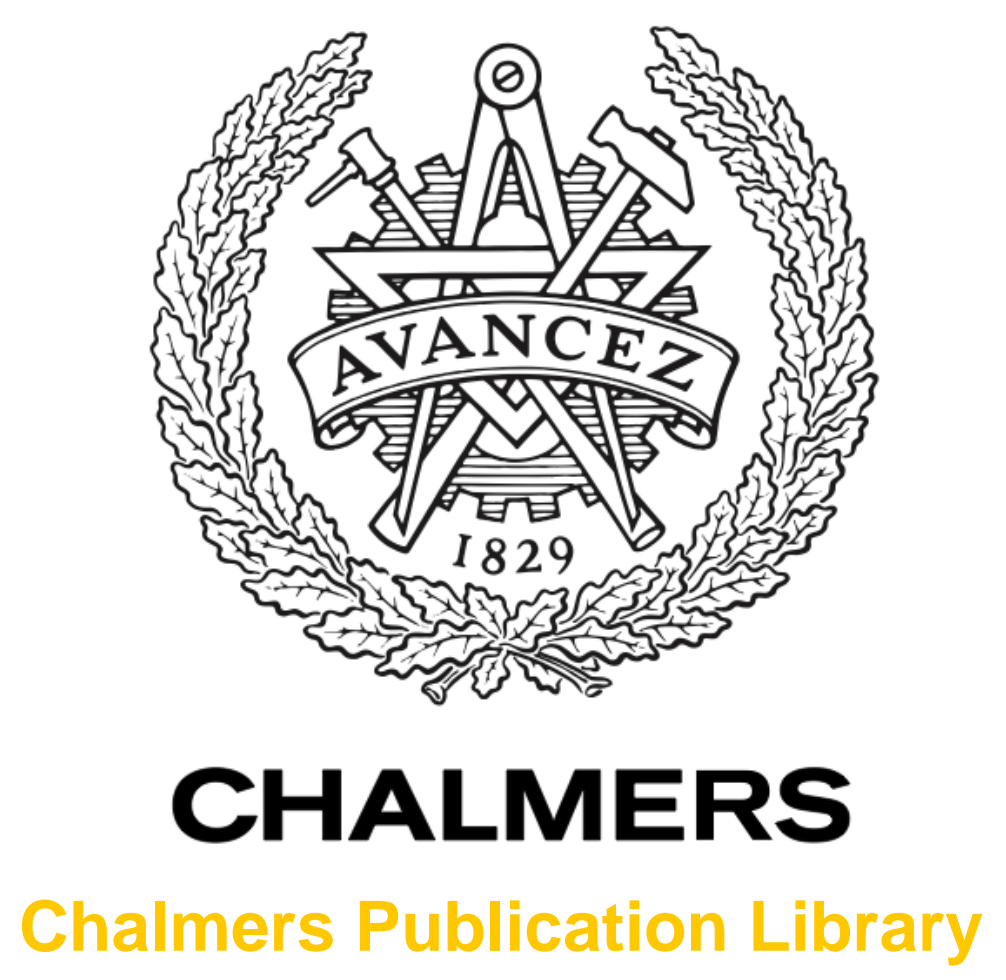

\title{
Assessing a proposal for an energy-based overall equipment effectiveness indicator through discrete event simulation
}

This document has been downloaded from Chalmers Publication Library (CPL). It is the author's version of a work that was accepted for publication in:

Proceedings of the 2014 Winter Simulation Conference

Citation for the published paper:

Barletta, I. ; Andersson, J. ; Johansson, B. et al. (2014) "Assessing a proposal for an energybased overall equipment effectiveness indicator through discrete event simulation".

Proceedings of the 2014 Winter Simulation Conference pp. 1096-1107.

Downloaded from: http://publications.lib.chalmers.se/publication/210125

Notice: Changes introduced as a result of publishing processes such as copy-editing and formatting may not be reflected in this document. For a definitive version of this work, please refer to the published source. Please note that access to the published version might require a subscription.

Chalmers Publication Library (CPL) offers the possibility of retrieving research publications produced at Chalmers University of Technology. It covers all types of publications: articles, dissertations, licentiate theses, masters theses, conference papers, reports etc. Since 2006 it is the official tool for Chalmers official publication statistics. To ensure that Chalmers research results are disseminated as widely as possible, an Open Access Policy has been adopted.

The CPL service is administrated and maintained by Chalmers Library. 


\title{
ASSESSING A PROPOSAL FOR AN ENERGY-BASED OVERALL EQUIPMENT EFFECTIVENESS INDICATOR THROUGH DISCRETE EVENT SIMULATION
}

\author{
Ilaria Barletta \\ Jon Andersson \\ Björn Johansson
}

Product and Production Development

Chalmers University of Technology

SE-41296, Gothenburg, SWEDEN

\author{
Gökan May \\ Marco Taisch \\ Management, Economics \& Industrial Engineering \\ Politecnico di Milano \\ Piazza Leonardo da Vinci 32 \\ Milano, 20133, ITALY
}

\begin{abstract}
New challenges demand that manufacturing companies adopt sustainable approaches and succeed in this adoption. Energy efficiency plays a key role in achieving sustainability goals, and performance indicators are necessary beyond measurement of data to evaluate energy efficiency. In this landscape, scalable and easy-to-understand metrics providing an energy competitiveness degree of manufacturing resources are currently missing. The study aims to test through simulation applicability and potential offered by a novel Energy Overall Equipment Effectiveness - Energy OEE - indicator for discrete manufacturing firms. A simulation of a discrete manufacturing $\mathrm{CNC}$ machine case is used to evaluate the applicability of using Energy OEE assessment for management decision support. As a result, this study paves the way to a better exploitation of data that energy monitoring and sensor technology aim to offer in the future.
\end{abstract}

\section{INTRODUCTION}

Key Performance Indicators (KPIs) turn measurement of a performance into meaningful information for stakeholders, who can visualize and further analyze for potential improvements. In this sense, current industrial competitive landscape and resulting needs require measurement of energy consumption supported by properly defined KPIs to track progress in achieving defined targets to foster competitiveness by improving energy performances.

This study aims at highlighting how to measure energy performances of discrete manufacturing factories through OEE-based-energy-related KPIs serving as a decision support tool for managing operations in a manufacturing plant to achieve competitiveness, and to illustrate and validate potential use of such KPIs using them within a virtual manufacturing facility modeled by Discrete Event Simulation (DES).

A methodology to design and implement novel energy performance indicators for discrete manufacturing firms developed in a previous research of the authors (Barletta, May, and Taisch 2012) represents the methodological background of this study.

A good example of an already-existing KPI to foster competitiveness by improving efficiency performances arising in the background study is the Overall Equipment Effectiveness (OEE) indicator. Thereby, proposing an "energy version" of the OEE, able to assess impacts of energy consumption losses rather than time losses, by testing its potential benefits through simulation, meets the needs previously illustrated, with the advantage of proposing an energy indicator for which structure and functioning are similar to an already well-known indicator used for tracking efficiency in the manufacturing industry. Henceforward, this energy alter ego of OEE will be called Energy OEE. 
The contents of this paper are outlined as follow: State of the art (Section 2), Research methodology (Section 3), Theoretical approach (Section 4), Practical approach (Section 5), Case implementation (Section 6), Discussion (Section 7), and Summary and Conclusions (Section 8).

\section{STATE OF THE ART}

Use of the OEE indicator can be considered almost an evergreen within industries' practices. First presented inside the Total Productive Maintenance (TPM) philosophy by Nakajima (1988), the OEE is generally measured in terms of the well-known six big losses (see the boxes underneath "Effectiveness Loss" in Figure 1). These are functions of availability rate, performance rate and quality rate of the machine, or production line or factory that constitute the three sub-indicators ("OEE Factors" in Figure 1), into which the OEE can be decomposed.

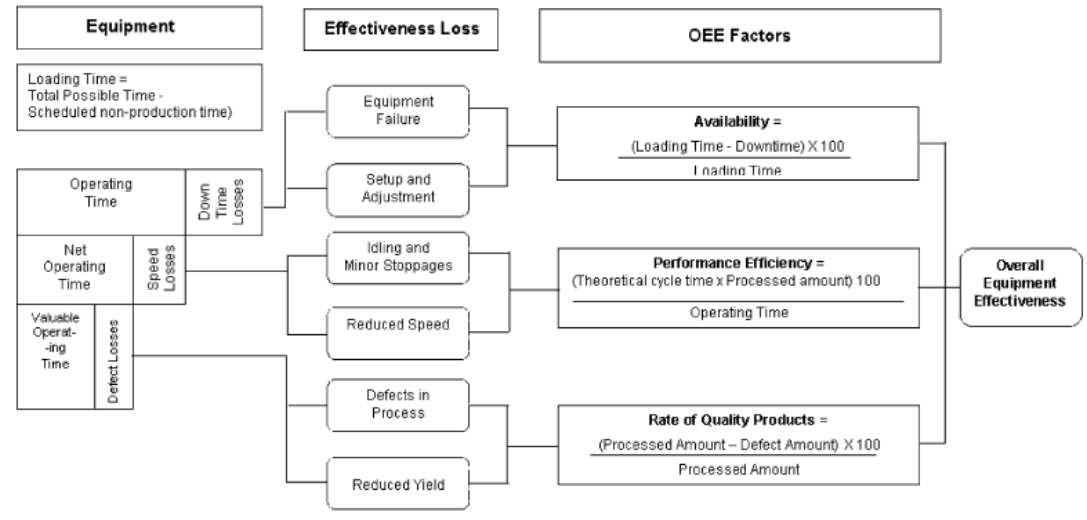

Figure 1: Overall Equipment Effectiveness calculation and losses (Nakajima 1989).

Modeling and simulation tools based on complex systems modeling are now standard in manufacturing. Heilala et al. (2008) considered and used Discrete Event Simulation (DES) as a tool for identification of production waste (e.g. waiting, work in process, inventories, transportation). Ingemansson and Bolmsjö (2004) showed different case studies prove DES potential to increase efficiency in a manufacturing system by studying production disturbances, later counted as losses pertaining to OEE calculations (Ingemansson and Oscarsson 2005). Finally, DES was used by Badiger and Gandhinathan (2008) to assist in recognizing the most convenient strategy for calculating OEE and defining optimum values for a manufacturing resource.

Muchiri and Pintelon (2008) showed that since no standard exists for calculating OEE, several versions of indicators hailing from OEE have been developed to accomplish several sectors and several scales. In the previous decade, several studies envisaged energy efficiency and energy consumption as some of the most critical drivers to foster sustainability in Manufacturing (Bunse et al. 2011; Morvay and Gvozdenac 2008). However, by consulting studies pertaining OEE-related indicators (Dal, Tugwell, and Greatbanks 2000; De Ron and Rooda 2005; Muchiri and Pintelon 2008), review papers on sustainability measurements (Dahl 2012; Joung et al. 2013) and specific reviews on energy-related indicators (Barletta, May, and Taisch 2012; Bunse et al. 2011), it was established that so far no attempt to develop an energyversion of the OEE indicator has been published in literature.

\section{RESEARCH APPROACH}

The Research Objective (RO) has been defined as testing the potential in using an Energy OEE indicator to track and assess the energy competitiveness degree of a manufacturing resource in discrete production by simulation, with the final aim of providing feedback on how to improve production management practices from a sustainability perspective. 
Research methodology involves the two pillars of the case study methodology and DES. Their use and role is described below:

- case study methodology has been used to build the methodology to develop energy-related indicators in the discrete manufacturing sector proposed in a previous study of the authors (Barletta, May, and Taisch 2012). This methodology is addressed in Section 4.

- DES is used to validate the applicability of proposed Energy OEE indicators addressing the previously identified gap. Figure 2 illustrates the research approach from a double perspective: a simulated environment and a real environment, depicting actors and objects involved and considering information flows among them.

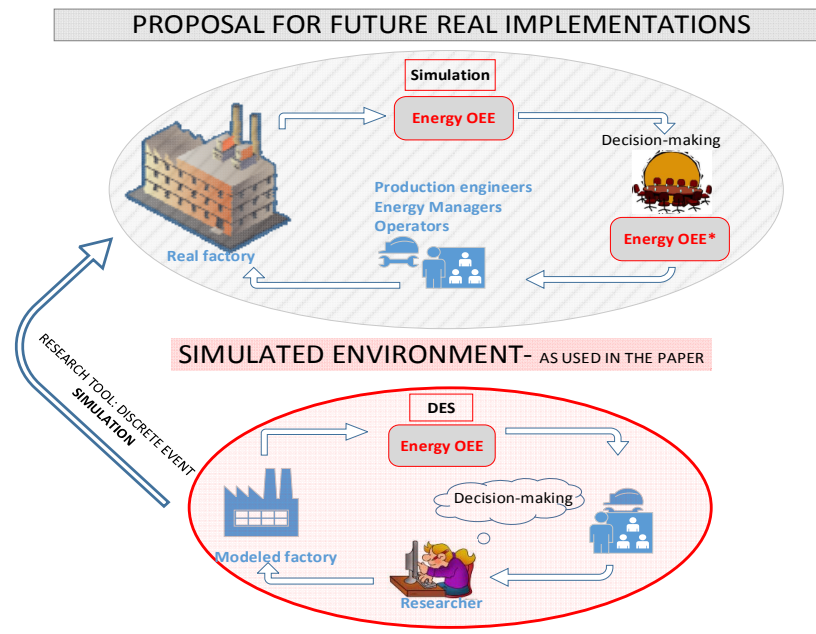

Figure 2: Research approach.

In Figure 2, a rational model of a real discrete manufacturing factory is created: assumptions, hypotheses and the description of the use case are presented in Section 6. Over simulation runs, statistics on time losses through production time and consequent energy consumptions of CNC machines are collected and matched to finally calculate Energy OEE and its sub-indicators. Researchers discuss Energy OEE value, compare other values of its sub-indicators and thus seek to improve energy performances of the systems' design, then implementing within the simulation model a future "to-be scenario" or possible alternatives a team of production engineers, energy managements and operators could have chosen in the same circumstances. To foster system energy competitiveness, a single, most preferable scenario or a limited set of alternatives will be tested, and the Energy OEE value -with its sub-indicators- analyzed and used as presented here. The research process, in Figure 2's red circle, strives to emulate what takes place in a real manufacturing environment, as in the grey circle. First, DES is used to calculate Energy OEE of a manufacturing resource according to system function and parameters. Subsequently, discussions of the simulation's results among all actors involved in operation management and energy performances take place within the decision-making process, and alternatives are generated considering not only the goal of improving Energy OEE value, but also other goals (e.g. KPIs tracked in the company's dashboard) and constraints (e.g. budget constraints, regulations). Thus, in the real world, combining Energy OEE and DES will serve as a decision support tool for using the proposed indicator, and to evaluate different manufacturing processes with main stakeholders, avoiding tests performed directly in the factory. Preferred alternatives to be tested through DES and resulting Energy OEE values are discussed as shown. Theoretical and practical findings arising from use case implementation will be discussed in Section 7, in order to assess whether and how the proposed indicator satisfies the needs and objectives of the study. 


\section{THEORETICAL APPROACH}

Figure 3 demonstrates the six steps of the cross-view methodology for developing novel energy-related indicators (Barletta, May, and Taisch, 2012). In the study just quoted, the development of the Energy OEE as an implementation of this methodology is shown in its entirety.

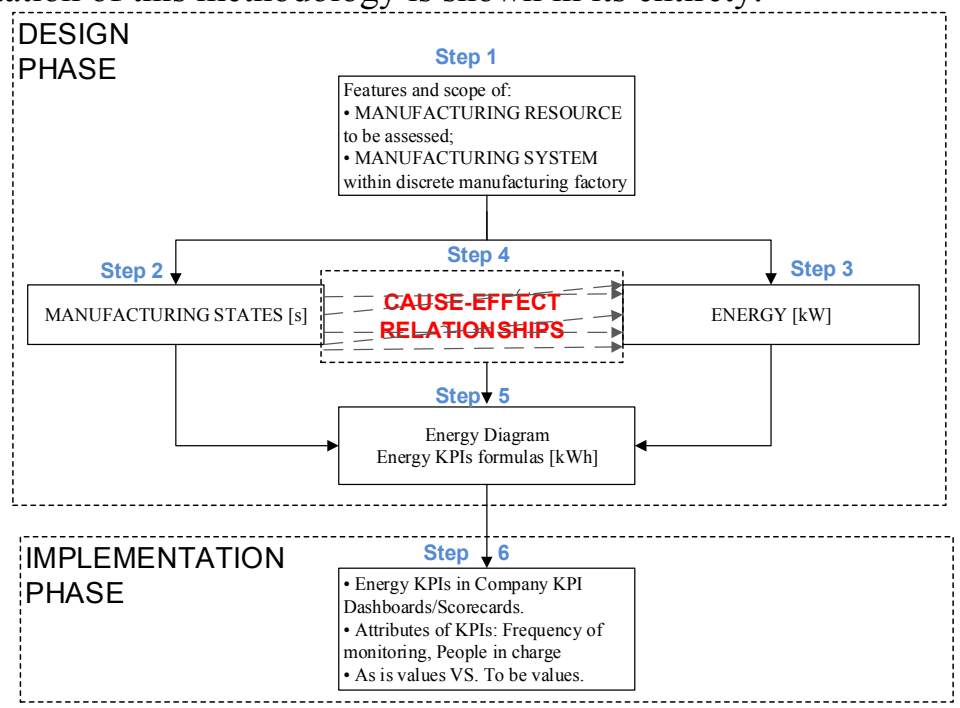

Figure 3: Definition steps to design and use the Energy OEE indicator (adapted from Barletta, May, and Taisch 2012).

Step 1 is to define the resource to be monitored through the Energy OEE and the manufacturing system boundaries in which it operates, for instance in terms of layout configuration, transformation processes and so forth.

Step 2 defines "manufacturing states", that is to say events causing time inefficiencies (measured in [s]) in the manufacturing system acting as energy consumption drivers for the manufacturing resource identified in step 1, and within the scope identified in step 1.

Step 3 defines energy states, that is to say electrical power requirements [kW] of a manufacturing resource, whose time length (and consequently, related energy consumption) can be potentially affected by events defined in step 2 .

Step 4 is the core step of the methodology: the cross-view methodology connects manufacturing states to energy states by shared investigation and identification of cause-effect relationships, to thus highlight the energy consumption connected to each state.

In step 5 energy losses obtained through the connections explained above are calculated and represented in different categories of energy consumption inside an "energy diagram" bar chart, like so time loss categories are grouped in Figure 1 (e.g. Operating Time, Net Operating Time). The energy diagram bar chart is structured as the energy alter-ego of Nakajima's bar chart diagram, (see the bar chart in Figure 1 underneath "Equipment" box). Therefore, definition and calculation of Energy KPIs can be finalized. The Energy KPIs are defined as indicators made up of energy consumption and production data gathered from the shop floor in discrete or continuous time and directed to highlight efficiency levels of different operations and manufacturing system management in energy consumption of productive energyconsuming resources. Step 5 closes the design phase of the cross-view methodology.

In the implementation phase (step 6), indicators developed are placed in KPI dashboards or KPI scorecards. In the study, we investigate how to effectively implement one of these indicators in manufacturing facilities through simulation, in order to fully serve as a decision support tool in operation management from a sustainable-and-energy-efficiency perspective. 


\section{PRACTICAL APPROACH}

This section shows how methodological design steps described in the previous section have been applied to develop the Energy OEE indicator. Testing the proposed Energy OEE in a modeled use case manufacturing line through DES will be described in Section 6. Application of steps follow the sequence in Figure 3 and is based on Barletta, May, and Taisch (2012).

Referring to the mapping of discrete manufacturing processes done in the report produced by A.D. Little (2000), step 1 focuses on CNC machines operating final shaping (material removing) processes, in particular cutting and machining, since this type of operation is widely discussed in the literature and industrial practices. Thereby, robust sources of information for validating the next steps of the study exist. Since this work aims to validate and discuss the implementation of a novel KPI, work scope has been kept as simple as possible: according to the ISA-95 standard (ANSI/ISA-95 2010), step 1 embraces a WorkUnit-level or Work-Centre-level, defined here as a CNC machine-level of measurement. Other features and elements of the scope deserving to be considered in step 1 have already been explored in Section 1 .

With regard to events affecting formula of indicators and thereby considered in the implemented DES, the study takes into account events affecting energy consumption of the CNC machine solely in charge of the operation management of the factory: events peculiarly stemmed from upstream supply chain or downstream supply chain will not be considered. This way to narrow the research scope does not limit the study: as discussed in Section 8, even future broader-scale applications can be originated and tested through DES.

In applying step 2, the manufacturing states considered in the use case correspond to the six big losses ("effectiveness losses") previously depicted in Figure 1.

In applying step 3, in this study, we assumed constant power requirements within each operational mode, although the actual power consumption fluctuates over time. The improvement of the energy performance of resources through monitoring and analysis is enabled exclusively by managerial levers (e.g. by improving line balancing or production scheduling). Figure 4 provides a generic example of discrete energy states of the productive resource modeled through a state diagram, depicting a possible energy behavior of a general CNC machine in a large set of situations (the energy state of maintenance has not been graphically represented in Figure 4 in order to keep it much easier to understand, since we have assumed that a failure can always take place when the machine is not in "Off" state).

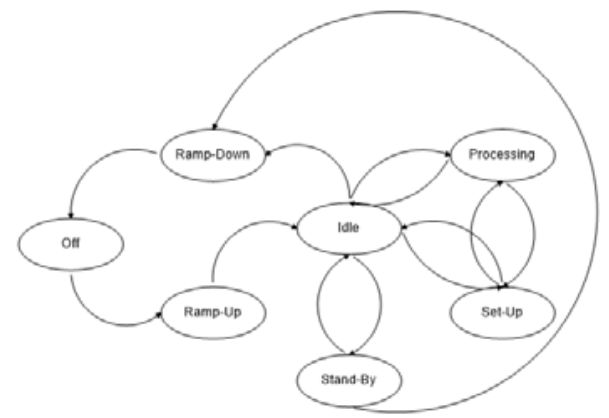

Figure 4: A sample energy state diagram for a CNC machine (Barletta, May, and Taisch 2012).

Within step 4, Ishikawa diagrams for investigating and mapping cause-effect relationships between manufacturing states and energy states are drawn. The resulting outcome is summed-up in a "cross-view" as in Figure 5 below, to illustrate both a "manufacturing view" and an "energy view" of a CNC machine. Figure 5 represents manufacturing states that affect energy states of production processes. It shows an application example of a CNC machine in a manufacturing line. The cause-effect relationships drawn within the application of the methodology strongly depend on understanding of system behavior (what 
variables impact on energy consumptions), on the hypotheses made to simplify the application of methodology and on energy data availability and process data availability.

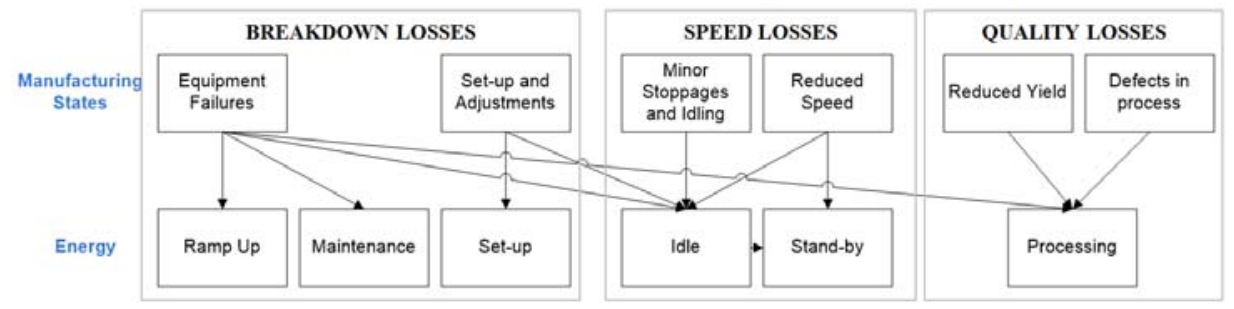

Figure 5: Cross-view methodology applied to Energy OEE: time losses affecting power requirements.

Within step 5, Figure 6 represents the energy diagram, as defined in Section 4, for the Energy OEE indicator. Energy inefficiencies caused by breakdown losses, subsequent speed and quality losses, are deducted from the total amount of energy consumed over the monitored time, using the OEE-approach to calculate sub-indicators expressed by Availability rate, Performance rate and Quality rate of the equipment. Taking into account only "unscheduled downtime", only Energy in Quality Losses, Energy in Speed Losses and Energy in Downtime Losses (marked in red) are considered, as in the OEE index. By adding energy spent in planned downtime, i.e. in planned maintenance, all losses in Figure 6 have to be considered, as Total Effective Equipment Performance (TEEP) does. Thus, a novel Energy TEEP, that is an energy-based TEEP, can be further calculated and assessed.

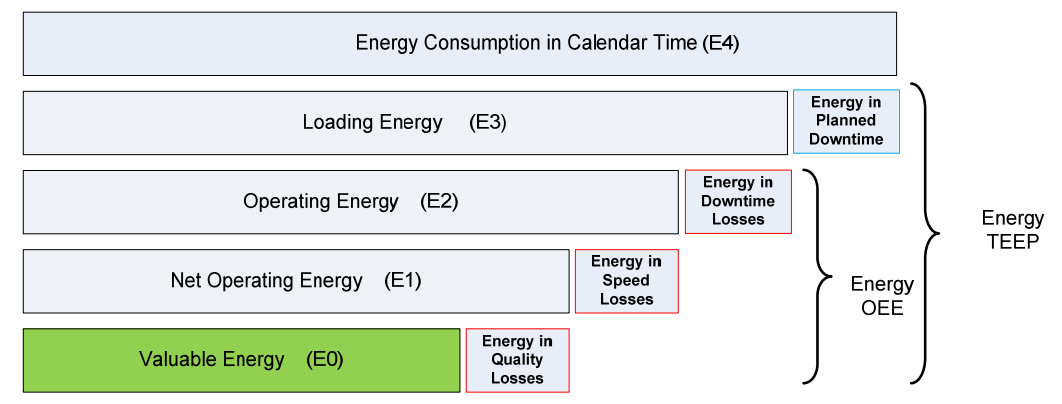

Figure 6: Energy OEE Diagram.

Valuable Energy (E0) represents energy spent for processing non-defective parts $Q_{n d}$. Processing is the power required for active processing of material removal $P_{p r}$ only, a sort of marketable and valuable energy. Energy in Quality Losses represents that spent for processing defective parts $Q_{d}$. Net Operating Energy (E1) is energy spent in processing the whole production $Q$, where $Q=Q_{n d}+Q_{d}$ : in fact, E1 represents production of $\mathrm{Q}$ according to the ideal cycle time or ideal throughput of the machine. Operating Energy (E2) is the result of Net Operating Energy added to energy spent over idle times and time in reduced speed (Energy in Speed Losses). Breakdown losses in Figure 5 have been split into "blocks" of Energy in Downtime Losses and Energy in Planned Downtime, depending on when energy is spent for maintenance activities; if spent over unscheduled (corrective) time or scheduled maintenance time (preventive). As considered in OEE index and in Figure 5, Energy in Downtime Losses includes set ups and adjustments, i.e. the tool changing. Energy in Planned Downtime includes energy spent for machine starts, according to the shift scheduling and the day-offs in calendar time. In the energy diagram, Loading Energy (E3) is equal to the sum of Operating Energy and Energy in Downtime Losses, while Energy in Calendar Time (E4) adds Loading Energy to Energy in Planned Downtime. Finally, Energy OEE is formulated as: 


$$
\text { Energy } O E E=E_{\text {availability }} \times E_{\text {performance }} \times E_{\text {quality }}
$$

At high level, Energy OEE sub-indicators formulas are respectively calculated as shown in Eq. 2:

$$
\text { Energy OEE }=\frac{\text { Operating Energy }}{\text { Loading Energy }} \times \frac{\text { Theoretical Energy consumption for } Q}{\text { Operating Energy }} \times \frac{Q_{n d}}{Q}
$$

$E_{\text {performance }}$ deserves particular focus. It represents how much the Operating Energy, as defined in this study, is far from ideal energy consumption when the machine is running at the same pace as its ideal cycle time, and subsequently no energy losses for time speed reduction occur. In the case of energy, the corresponding measure of the cycle time is represented by the Specific Energy Consumption (SEC) indicator, presented for the first time by Phylipsen, Blok, and Worrell (1997). Accordingly, the standard (or ideal) value for representing Theoretical Energy consumption per part is constituted by the lower energy consumption per part (thus, an Ideal SEC), or alternatively, by the largest number of parts produced by a certain amount of energy (Ideal Energy Efficiency, defined as the inverse ratio of the Ideal $S E C$ ). An Ideal SEC may be equal to energy spent for exclusively processing one part, at most plus energy for changing tool operations to shape the features of the part. For simplicity, we consider the Ideal $S E C$ as Ideal $S E C=E_{p r}=T_{p r} \times P_{p r}$, or the energy for processing one part at a time $T_{p r}$ (where $T_{p r}$ is the processing time of the part) requiring power $P_{p r}$. Thus, $E_{\text {performance }}$ is presented again below:

$$
E_{\text {performance }}=\frac{\text { Ideal } S E C \times Q}{\text { Operating Energy }}
$$

Finally, simplifying (2), the aggregated formula of Energy $O E E$ is:

$$
\text { Energy } O E E=\frac{\text { Ideal } S E C \times Q_{n d}}{\text { Loading Energy }}
$$

Considering the contribution of planned downtime, the Energy TEEP is calculated as follows:

$$
\text { Energy TEEP }=\frac{\text { Valuable Energy }}{\text { Energy Consumption in Calendar Time }}
$$

It represents a sort of "lean energy indicator", since it assesses how much valuable energy has been used in relation to total energy consumption.

One of the most crucial points pertaining to the application of Energy OEE within a certain use case is that the consideration of parameters and variables constituting formulas of every sub-indicators strongly depends on the characteristics of the system defined within step 1, as well as data availabilities and relevance of the event affecting total energy consumption. For instance, if the system produces a product mix that requires set-ups, then the number of tool changing within the production sequence and the energy spent for each set up must be included in the calculation of the Loading Energy.

\section{CASE IMPLEMENTATION}

This chapter illustrates the descriptive use case designed and modeled through DES to show how the Energy OEE indicator can act as decision support for manufacturing in a DES environment. The purpose of the simulation test is to exemplify how this can be used and to test the potential.

\subsection{Description of Use Case}

The modeled system is a simple manufacturing line machining casted steel for the car industry. It consists of two CNC stations and one assembly station run by two operators. The system processes only one product variant and no set up is required. Table 1 provides numerical and qualitative data about the most relevant model input information for the three system stations. Distribution of cycle times, Mean Time To 
Failure (MTTF), Mean Time To Repair (MTTR) and percentage of $Q_{d}$ among $Q$ define the manufacturing states and how they impact on Energy OEE as selected in this use case. Cycle times depend on the exact variant of product and are modeled as a triangular distribution. Breakdowns cause shutdown of Stations 1 and 2. MTTF is modeled according to an exponential distribution, whilst MTTR is modeled according to a triangular distribution. Mean values of each distribution are shown in Table 1 below. From the seventh to the last line of the table, station power requirements have been provided. In particular, $P_{d}$ is the power required when the station is in failure state, waiting to be repaired, $P_{m}$ is the power required when the station is being repaired using measures that require power, and $P_{i}$ is the power required when the station is on and not processing, that is power that keeps components standing by to process parts.

Table 1: A set of inputs to the model: manufacturing and energy states of system stations.

\begin{tabular}{|l|l|l|l|}
\hline \multicolumn{1}{|c|}{ INPUT } & Station 1 - Drilling & Station 2 - Fine turning & Station 3 - Assembly \\
\hline Function & $\begin{array}{l}\text { To drill several holes for casting } \\
\text { metal plate. }\end{array}$ & $\begin{array}{l}\text { To shape the part and make it fit the } \\
\text { dimension and surface criteria. }\end{array}$ & $\begin{array}{l}\text { To assemble additional parts and } \\
\text { pack the product unto pallets. }\end{array}$ \\
\hline \# entities & 1 machine & 2 machines & 1 station, 2 operators \\
\hline Cycle time $[\mathrm{s}]$ & Triangular min 32, max 38.4 & Triangular min 43, max 51.6 & Triangular min 21, max 45 \\
\hline MTTF[h] & Exp mean 14 & Exp mean 16 & - (always available) \\
\hline MTTR[h] & Exp mean 0.17 & Exp mean 1.5 & - (always available) \\
\hline $\mathrm{Q}_{\mathrm{d}} \%$ & $1 \%$ & $1 \%$ & $3 \%$ \\
\hline $\mathrm{P}_{\mathrm{pr}}[\mathrm{kW}]$ & 10 & 13.84 & 25 \\
\hline $\mathrm{P}_{\mathrm{d}}[\mathrm{kW}]$ & 1 & 1 & - \\
\hline $\mathrm{P}_{\mathrm{m}}[\mathrm{kW}]$ & 4.64 & 7.56 & - \\
\hline $\mathrm{P}_{\mathrm{i}}[\mathrm{kW}]$ & 4.64 & 7.56 & - \\
\hline
\end{tabular}

Parts are moved from Station 1 to Station 2 by conveyor containing at most 3 parts. Figure 7 shows the modeled system: the red circle indicates Station 1 as the station for which Energy OEE and other indicators will be calculated and discussed. The conveyor takes 10 seconds to transfer parts to the next station.

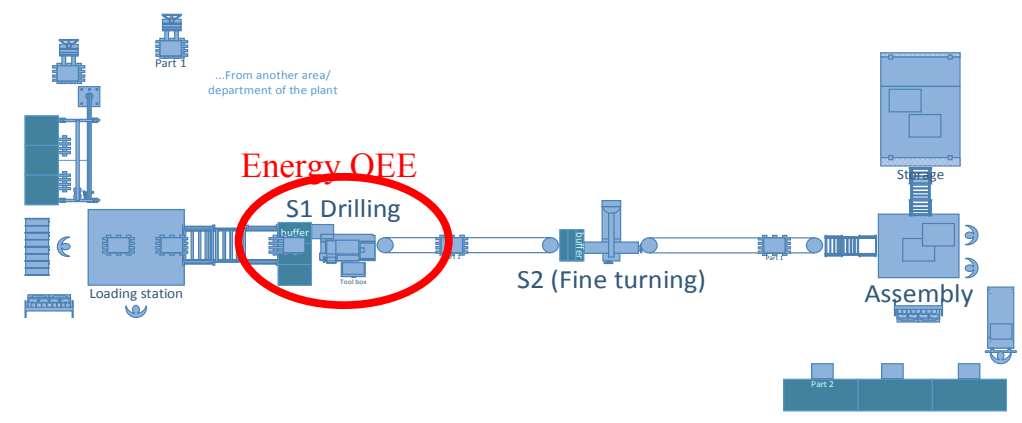

Figure 7: A graphical representation of the modeled manufacturing line.

The implemented DES can provide data about system and component efficiency performances from both time and energy perspectives. Figure 8 highlights selected output metrics of the simulation model for supporting the discussion of results of Status Quo scenario compared with results from the three scenarios that will be later generated. The values reported in Figure 8 stem from the design of experiments applied to all the scenarios evaluated in the DES, that are going to be described in the next section.

\subsection{Result Run Scenarios and Discussion}

Looking at the results of Status Quo, $E_{\text {performance }}$ indicator's value is recognizable as the major responsible for the overall efficiency loss. Therefore, scenarios designed and presented here focus on improving the Energy OEE by reducing unnecessary energy spent by small stoppages and speed losses. The three experiments tested in the simulation model, named Scenario 1, Scenario 2 and Scenario 3, aim to improve 
the Energy OEE by looking at different aspects of the production performances from an operationsmanagement perspective. In particular:

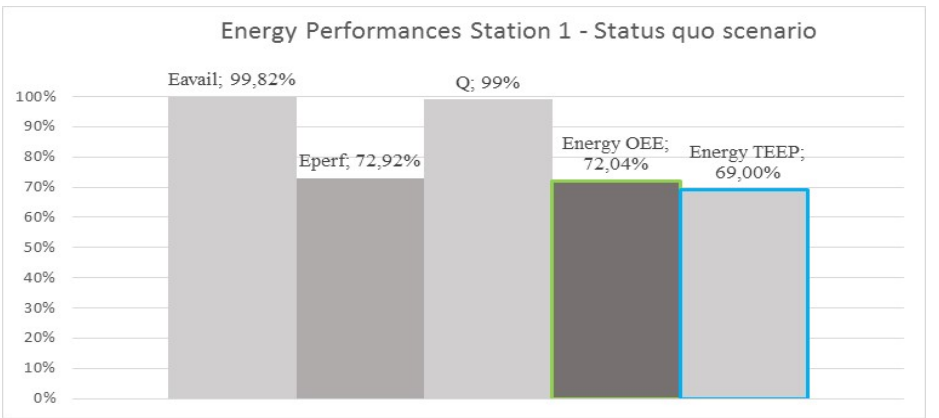

Figure 8: A set of outputs from the model: Energy performance indicators selected for discussions.

- Scenario 1 focuses on balancing other entities of the system but Station 1: the cycle time of Station 2 has actually been improved by $12 \%$, moving from $43 \mathrm{~s}$ to $38 \mathrm{~s}$. However, we assumed that the total value-added energy to process the product is still the same of the original scenario. Thereby, this is equivalent to optimize time and procedures pertaining non-valuable (that is, nonprocessing) activities of Station 2's CNC machine;

- Scenario 2 focuses on Station 1, in an attempt to stabilize its variability: the triangular distribution parameters have been modified from a triangular distribution with max 38.6 to a triangular distribution with max 35.2, by keeping the same min (32) of triangular distribution of Status Quo scenario. This is equivalent to reduce by half speed losses affecting $E_{\text {performance }}$ indicator;

- Scenario 3 acts from a different perspective to the others. It chooses to focus on Station 1 and improve $E_{\text {performance }}$ by deliberately "neglecting" careful maintenance of the station, but by maintaining the Quality rate. Very high availability of Station 1 is not a paramount priority, and a "softer" maintenance policy could reduce maintenance costs. Station MTTF has been diminished from $50200 \mathrm{~s}$ to $49000 \mathrm{~s}$, the Maintenance Mean has been diminished from $7200 \mathrm{~s}$ to $7000 \mathrm{~s}$ and Total time dedicated to Maintenance has been diminished from $86400 \mathrm{~s}$ to $86000 \mathrm{~s}$.

The DES model is changed according to the scenario and the results are compared. Each experiment embodies 20 runs, and each run stopped by the model when 10000 parts had been produced. Mean and standard deviations of statistics of energy consumptions and defective parts $Q_{d}$ have been collected and presented in Table 2. Each scenario has been tested by analyzing the Energy OEE indicator differences from Status Quo. The comparison tests if there is any significant change to the Energy OEE values. The use of a one-tailed t-test is to see whether there is any statistical difference between the results. A comparison of these scenarios and the Status Quo scenario is summed-up in Table 3 below. The columns contain proper metrics selected for comparison in the previous section (see Figure 8). The highest performance increase was gained from Scenario 1.

Table 2: Mean, and Standard deviations in brackets, of output data from the experiments. Bold is statistically significant from Status Quo using one-tailed t-test.

\begin{tabular}{|l|l|l|l|l|}
\hline \multicolumn{1}{|c|}{$\Sigma$ Energy Consumption $[\mathrm{kWh}]$} & Status quo & Scenario 1 & Scenario 2 & Scenario 3 \\
\hline Valuable Energy & $879(0.973)$ & $880(0.887)$ & $879(1.02)$ & $879(0.902)$ \\
\hline Net Operating Energy & $888(0)$ & $889(0)$ & $888(0)$ & $888(0)$ \\
\hline Operating Energy & $1218(92.1)$ & $\mathbf{1 1 2 8}(\mathbf{3 2 . 3})$ & $\mathbf{1 1 7 6 ( 4 8 . 6 )}$ & $1208(55.7)$ \\
\hline Loading Energy & $1221(92.5)$ & $\mathbf{1 1 3 0}(\mathbf{3 2 . 3})$ & $\mathbf{1 1 7 8 ( 4 9 . 3 )}$ & $1210(56.2)$ \\
\hline Energy Consumption in Calendar Time & $1274(101)$ & $\mathbf{1 1 8 1}(\mathbf{3 6 . 3})$ & $1237(52.1)$ & $1270(64.5)$ \\
\hline Defective parts & $103(10.9)$ & $101(9.98)$ & $101(11.5)$ & $103(10.1)$ \\
\hline
\end{tabular}


Barletta, Andersson, Johansson, May, and Taisch

Table 3: Comparison of results among the three scenarios.

\begin{tabular}{|l|c|c|c|c|c|}
\hline OUTPUT [\%] & $E_{\text {availability }}$ & $E_{\text {performance }}$ & Quality & $\begin{array}{l}\text { Energy } \\
\text { OEE }\end{array}$ & $\begin{array}{l}\text { Energy } \\
\text { TEEP }\end{array}$ \\
\hline Status quo & 99.82 & 72.92 & 99 & 72.04 & 69.00 \\
\hline Scenario 1 & 99.79 & 78.81 & 99 & 77.85 & 74.52 \\
\hline Scenario 2 & 99.79 & 75.58 & 99 & 74.66 & 71.08 \\
\hline Scenario 3 & 99.81 & 73.56 & 99 & 72.66 & 69.26 \\
\hline
\end{tabular}

According to Table 2, Scenario 1 was the only scenario that was observed to have a significant lower energy consumption on the total time. Scenario 1 will give the company a $7 \%$ higher Energy OEE, whereas the other scenarios did not have a significant overall effect. Values of the single indicators forming the Energy OEE give the analyst a hint of what are the performances to improve from an operation-management perspective. As a matter of fact, from the results of Status Quo's Energy OEE, the analyst knows where to focus the attention upon to improve the total energy performance. However, the analyst still needs to investigate, as done by generating and testing alternative simulation scenarios, what exactly is the problem negatively affecting the Energy OEE. Besides, the proposed approach enables the simulation of more complex scenarios where different system parameters can be modified simultaneously (i.e. acting on maintenance and quality in parallel).

\section{DISCUSSION}

By analyzing the three sub-indicators of the Energy OEE, detecting the source of the major energy consumption impact on the overall energy equipment effectiveness becomes extremely immediate. In generating alternatives to improve the level of energy competitiveness, decision-makers can simulate these via DES and evaluate each scenario fully, considering results from simulation and existing constraints, trade-off objectives, costs and consequences involved in implementing the alternatives.

The need for significant measurements calls for adequate monitoring periods, capable of reducing the impact of short-term special events that play a negligible role in sizing production resources. Industries that are better candidates for such a proposal are those running with a level of automation able to justify investment of a high-granularity monitoring that Energy OEE requires. Other well-strengthened simulation approaches in manufacturing, apart from DES, might be used to test the Energy OEE within a certain scenario and scope of analysis. For instance, Jahangirian et al. (2010) pointed out how Petri-net simulation, Monte Carlo simulation or Agent Based Simulation (ABS) lend themselves better in supporting decision-making processes on scheduling and resource allocation, whereas System Dynamics (SD) well satisfies decision making processes on strategy and supply chain management.

Finally, the simulation model used here along with the flexible structure of designed indicators, allows upper-scale analyses of the manufacturing resource (e.g., equipment, process, department, factory), but is not necessarily circumscribed by a single station. The aggregation of data taken from model statistics (and from a "real" shop floor) and following calculations in the Energy OEE, enable broader scopes of investigation.

\section{SUMMARY AND CONCLUSIONS}

The ability to measure and track competitiveness in reaching energy efficiency and sustainability goals can now count as a competitive advantage in itself for manufacturing firms. So far, in the state of the art, no energy indicators adding value in the form of energy competitiveness information exist.

To compensate, this study proposes a novel OEE-based-energy-related KPI that, combined with DES, serves as a decision support tool to track and achieve energy competitiveness. According to results in Section 6, the use of the Energy OEE combined with DES allows production engineers and other stakeholders in the manufacturing system to visualize, track, claim and benchmark a quick and easy-to- 
understand measure of the level of energy competitiveness achieved by the system. The combined use of Energy OEE with DES allows improvement to both energy efficiency and system productivity. This proposal enables a proper diagnosis regarding operation management activities, policies and practices that significantly affect the system energy consumption scope. Activities might stem from decisions taken about production shifts, preventive maintenance, or production scheduling rules.

Finally, this study paves the way to a full adoption of the Energy OEE indicator as one of the metrics put into the multi-objective functions to be optimized in production management problem-solving, with the purpose of helping stakeholders to select the best alternative for a specific case.

\section{REFERENCES}

ANSI/ISA-95 00.01-2010. 2010. “(IEC 62264-1 Mod) Enterprise-Control System Integration - Part 1: Models and Terminology." American National Standards Institute/International Society of Automation.

Badiger, A. S., and R. Gandhinathan. 2008. "A proposal: evaluation of OEE and impact of six big losses on equipment earning capacity." International Journal of Process Management and Benchmarking 2 (3): 234-248.

Barletta, I., G. May, and M. Taisch. 2012. "Una metodologia cross view di sviluppo di key performance indicator di efficienza energetica." Master Science Thesis, Department of Management, Economics and Industrial Engineering, Politecnico di Milano, Italy. Accessed May 8, 2014. http://hdl.handle.net/10589/69303.

Bunse, K., M. Vodicka, P. Schönsleben, M. Brülhart, and F.O. Ernst. 2011. "Integrating energy efficiency performance in production management-gap analysis between industrial needs and scientific literature." Journal of Cleaner Production 19 (6): 667-679.

Dahl, A. L. 2012. "Achievements and gaps in indicators for sustainability." Ecological Indicators 17:1419.

Dal, B., P. Tugwell, and R. Greatbanks. 2000. "Overall equipment effectiveness as a measure of operational improvement-a practical analysis." International Journal of Operations \& Production Management 20 (12): 1488-1502.

De Ron, A. J., and J. E. Rooda. 2005. "Equipment effectiveness: OEE revisited." IEEE Transactions on Semiconductor Manufacturing 18 (1): 190-196.

Fleischer, J., U. Weismann, and S. Niggeschmidt. 2006. "Calculation and optimisation model for costs and effects of availability relevant service elements." In Proceedings of the 13th International Conference on Life Cycle Engineering, 675-680.

Heilala, J., K. Helin, and J. Montonen. 2006. "Total cost of ownership analysis for modular final assembly systems." International Journal of Production Research 44 (18-19): 3967-3988.

Heilala, J., S. Vatanen, H. Tonteri, J. Montonen, S. Lind, B. Johansson, and J. Stahre. 2008. "Simulationbased sustainable manufacturing system design." In Proceedings of the 2008 Winter Simulation Conference, edited by S. J. Mason, R. R. Hill, L. Mönch, O. Rose, T. Jefferson, J. W. Fowler, 1922-1930. Piscataway, New Jersey: Institute for Electrical and Electronics Engineers, Inc.

Huang, S.H., J.P. Dismukes, A. Mousalam, R.B. Razzak, and D.E. Robinson. 2003. "Manufacturing productivity improvement using effectiveness metrics and simulation analysis." International Journal of Production Research 41 (3): 513-527.

Ingemansson, A., and G.S. Bolmsjö. 2004. "Improved efficiency with production disturbance reduction in manufacturing systems based on discrete-event simulation." Journal of Manufacturing Technology Management 15 (3): 267-279.

Ingemansson, A., and J. Oscarsson. 2005. "Discrete event simulation and automatic data collection improve performance in a manufacturing system." In Proceedings of the 2005 Winter Simulation 
Conference, edited by M. E. Kuhl, N. M. Steiger, F. B. Armstrong, and J. A. Joines, 1441-1445. Piscataway, New Jersey: Institute for Electrical and Electronics Engineers, Inc.

Institute for Prospective Technological Studies. 2003. "The Future of Manufacturing in Europe 20152020: The Challenge for Sustainability." Scenario Report (summary).

Jahangirian, M., T. Eldabi, A. Naseer, L. K. Stergioulas, and T. Young. 2010. "Simulation in manufacturing and business: A review." European Journal of Operational Research 203(1):1-13.

Joung, C. B., J. Carrell, P. Sarkar, and S. C. Feng. 2013. "Categorization of indicators for sustainable manufacturing." Ecological Indicators 24: 148-157.

Little, A. D. 2000. "Overview of Energy Flow for Industries in Standard Industrial Classifications 2039." Final summary report to the US Department of Energy, Office of Industrial Technology.

Muchiri, P., and L. Pintelon. 2008. "Performance measurement using overall equipment effectiveness (OEE): literature review and practical application discussion." International Journal of Production Research 46 (13): 3517-3535.

Nakajima, S. 1988. Introduction to TPM: Total Productive Maintenance. Cambridge, MA: Productivity Press.

Nakajima, S. 1989. TPM Development Program. Cambridge, MA: Productivity Press.

Phylipsen, G. J. M., K. Blok, and E. Worrell. 1997. "International comparisons of energy efficiency methodologies for the manufacturing industry." Energy Policy 25 (7): 715-725.

\section{AUTHOR BIOGRAPHIES}

ILARIA BARLETTA is a $\mathrm{PhD}$ Student in the field of sustainability assessment in discrete manufacturing system at Product and Production Development, Chalmers University of Technology. Her research interest lies in the areas of operation management techniques to foster efficiency performances, Key Performance Indicators design and implementation. Her email address is ilaria.barletta@chalmers.se.

JON ANDERSSON is a PhD student in the field of virtual production system at Product and Production Development, Chalmers University of Technology. He is currently active in the field of simulation of production flows and in the project EcoProIT (http://www.ecoproit.com), which uses DES for environmental impact assessments. His email address is jon.andersson@chalmers.se.

BJÖRN JOHANSSON is an assistant professor at Product and Production Development, Chalmers University of Technology. His research aims at utilizing virtual applications to achieve more sustainable manufacturing industries. He explores specific methodologies and tools for analyzing flows throughout a product lifecycle, addressing social environmental and economic key performance indicators to improve the real world performance. His email address is bjorn.johannson@chalmers.se.

GÖKAN MAY holds a PhD in Management, Economics and Industrial Engineering at Politecnico di Milano, where he teaches Operations Management. His main research specialties include ICT-enabled sustainable and energy-efficient manufacturing, eco-efficient design of production facilities, and designing worker-centric factories of the future. His email address is gokan.may@polimi.it.

MARCO TAISCH is a Full Professor at the Department of Management, Economics and Industrial Engineering of Politecnico di Milano, where he teaches the course of Advanced and Sustainable Manufacturing Systems. His research interests are in the field of Operations and Supply Chain Management and Product Life Cycle Management. His email address is marco.taisch@polimi.it. 